Singh, B. \& Mitchison, D. A. (1955). J. gen. Microbiol. 12, 76-84.

\title{
Bactericidal Activity of Streptomycin and Isoniazid in Combination with $p$-Aminosalicylic Acid against Mycobacterium tuberculosis
}

\author{
By BALBIR SINGH* AND D. A. MITCHISON $\dagger$ \\ Department of Bacteriology, Postgraduate Medical School of London, \\ Ducane Road, London, W. 12
}

SUMMARY: The bactericidal activity of streptomycin, isoniazid and combinations of streptomycin and isoniazid against tubercle bacilli growing in Tween albumin medium was measured with and without the addition of $p$-aminosalicylic acid (PAS). When the concentrations of these compounds were about 4 to 16 times their minimal inhibitory concentrations, PAS did not influence this activity, but it was slightly increased when the concentrations were 10 times higher (equal to peak serum concentrations in treated patients). Combinations of the low concentrations of PAS + streptomycin or PAS + isoniazid usually only delayed the emergence of drugresistant bacilli, whereas combinations of the higher concentrations suppressed their growth.

Lehmann (1946) reported that $p$-aminosalicylic acid (PAS) inhibited the growth of Mycobacterium tuberculosis. This inhibition was, however, only partial and PAS was less effective than streptomycin or isoniazid in the treatment of both human pulmonary tuberculosis (Medical Research Council, 1950) and experimental tuberculosis in mice and guinea pigs (McClosky, Smith \& Frias, 1948; Swedburg, 1949; Swedburg \& Widstrom, 1948; Steenken $\&$ Wolinsky, 1950). PAS is now usually used in treatment together with streptomycin or isoniazid. The main purpose of this combined therapy is to prevent the emergence of drug-resistant strains of tubercle bacilli which have occurred in about two-thirds of cultures from patients with acute pulmonary tuberculosis who have been treated with streptomycin or isoniazid alone and in about a quarter of cultures from those treated with PAS alone over a period of 3 months (Medical Research Council, 1948, 1950, 1953b). Combined treatment with either streptomycin and PAS or isoniazid and PAS was found to decrease markedly the incidence of drug-resistant strains (Medical Research Council, 1950, 1953c). The response to combined treatment, measured either in terms of radiological improvement or of sputum conversion, was also slightly superior to the response when streptomycin or isoniazid were used alone.

In considering in vitro experiments designed to elucidate the combined activity of PAS with streptomycin or isoniazid two types of experimental systems can be used. In the first of these, sensitive organisms are assumed to be capable of multiplication in tuberculous lesions during treatment so that the effectiveness of the treatment would be limited by the ability of the drugs

* Colombo Plan Fellow.

$\dagger$ In receipt of a grant from the Medical Research Council. 
to penetrate in bacteriostatic concentrations to the sites where such multiplication occurred. On this assumption improved results would be expected if the minimal inhibitory concentration of the drugs together was less than that of either drug alone. Vennesland, Ebert \& Bloch (1948) found marked enhancement of inhibition when concentrations of either streptomycin or PAS that were moderately inhibitory alone were mixed with a non-inhibitory concentration of the other drug. Furthermore, when multiplying bacilli were subjected to gradually increasing streptomycin concentrations during repeated cultivation in sub-bacteriostatic concentrations of the drug, the addition of very low concentrations of PAS prevented the emergence of resistant strains (Graessle \& Pietrowski, 1949; Vennesland et al. 1948). When small inocula of a sensitive strain were added to tubes containing serial dilutions of isoniazid, the addition of low concentrations of PAS also prevented the shift in the inhibitory end-point due to the growth of resistant bacilli (Knox, King \& Woodroffe, 1952; Aitoff, 1952). The second experimental system assumes that bacteriostatic drug concentrations are present throughout tuberculous lesions soon after the start of treatment. The effectiveness of combined treatment would then depend on the speed with which the initial and usually large population of sensitive bacilli was killed. Reasons for supposing that this approach, in which emphasis is laid on the bactericidal activity of the drugs, is more likely to be correct have been given elsewhere (Mitchison, 1954b). An attempt was therefore made to study the influence of PAS on the bactericidal activity of streptomycin or isoniazid and the extent to which it can modify the emergence of drug-resistant bacilli from relatively large sensitive populations.

\section{METHODS}

Screw-capped bottles containing $20 \mathrm{ml}$. of a culture of the $\mathrm{H} 37 \mathrm{Rv}$ strain of Mycobacterium tuberculosis, grown for 9-10 days in modified Dubos and Davis Tween albumin medium (Medical Research Council, 1953 $a$ ), were centrifuged for $10 \mathrm{~min}$. to remove the larger aggregates of bacilli. The supernatant fluid was removed and stained films from it showed that $80 \%$ of the separate bacillary units consisted of single bacilli or pairs of bacilli.

A volume of $0.5 \mathrm{ml}$. of this supernatant was added to $4.5 \mathrm{ml}$. of Tween albumin medium (in screw-capped bottles) containing different concentrations of streptomycin, isoniazid or the dihydrate of the sodium salt of PAS (NaPAS). Two concentrations of each of these drugs were used. The higher of these (streptomycin 20 units $/ \mathrm{ml}$., isoniazid $2 \mu \mathrm{g} . / \mathrm{ml}$., NaPAS $100 \mu \mathrm{g} . / \mathrm{ml}$.) corresponded to the approximate peak serum concentrations found in patients treated with streptomycin at $1 \mathrm{~g}$./day, isoniazid $200 \mathrm{mg}$./day or NaPAS 20 g./day (Singh \& Mitchison, 1954; Nilsson, 1953). The lower concentrations (streptomycin 2 units $/ \mathrm{ml}$., isoniazid $0.2 \mu \mathrm{g} . / \mathrm{ml}$., NaPAS $10 \mu \mathrm{g} . / \mathrm{ml}$.) were about 4 to 16 times the minimum concentration that inhibits the growth of tubercle bacilli in Tween albumin medium (Medical Research Council, 1953a; Mitchison, 1952). A control bottle not containing drug was included in each experiment. The bottles were incubated at $37^{\circ}$. There was no change in the PAS concentration, estimated by the method of Newhouse \& Klyne (1949) 
during a 3-month period of incubation. At intervals, $0.5 \mathrm{ml}$. samples were removed from these bottles for viable counts on oleic acid + albumin + agar plates using a calibrated dropping pipette and loop as described by Mitchison (1953). The diluent was Tween albumin medium. The plates were sealed with wax-coated cellulose tape and were incubated for 4 weeks. Colonies were counted with a plate microscope.

Where the presence of resistant organisms was suspected, sensitivity tests to streptomycin, isoniazid and PAS were carried out by the Medical Research Council $(1953 a)$ methods. In one experiment cultures were injected into guinea-pigs by the intramuscular route.

\section{RESULTS}

\section{Bactericidal activity}

The first experiment (Fig. 1) was a comparison between the bactericidal activity of streptomycin alone (in concentrations of 2 and $20 \mathrm{units} / \mathrm{ml}$.) and of combinations of streptomycin and PAS. Two combinations were used: one with the low therapeutic concentrations of streptomycin 2 units $/ \mathrm{ml}$. and NaPAS $10 \mu \mathrm{g} . / \mathrm{ml}$. and the other with the high therapeutic concentrations of streptomycin 20 units $/ \mathrm{ml}$. and NaPAS $100 \mu \mathrm{g} . / \mathrm{ml}$. Controls containing NaPAS $10 \mu \mathrm{g} . / \mathrm{ml}$. and $100 \mu \mathrm{g} . / \mathrm{ml}$. alone were included. Fig. 2 shows a similar experiment in which isoniazid in concentrations of 0.2 or $2 \mu \mathrm{g} . / \mathrm{ml}$. was used in place of streptomycin. In a third similar experiment(Fig. 3) the activity of streptomycin and isoniazid together was compared with the activity of the mixture of streptomycin, isoniazid and PAS.

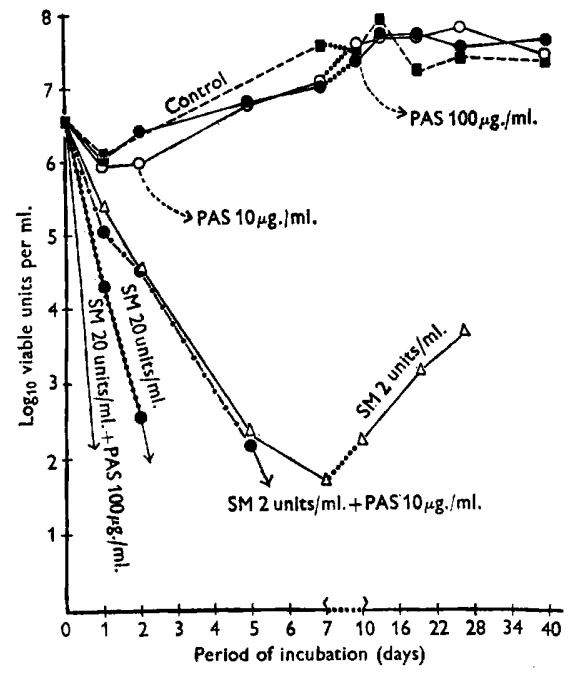

Fig. 1. Bactericidal action of streptomycin alone and in combination with PAS.

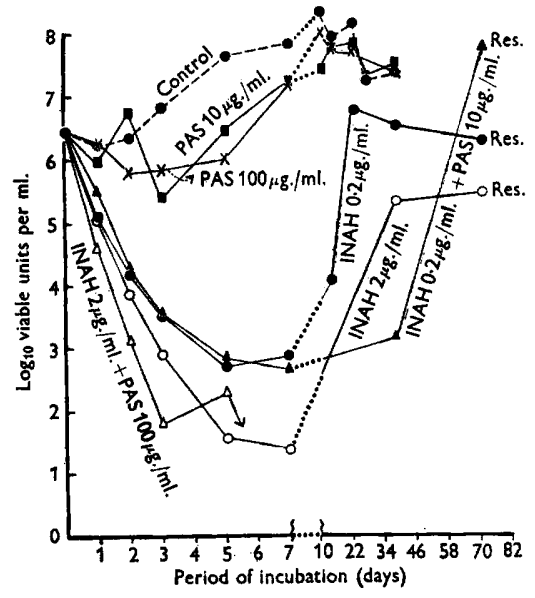

Fig. 2. Bactericidal action of isoniazid alone and in combination with PAS.

In these three experiments PAS alone slightly delayed the growth of the cultures (Figs. 1 and 2 ) or did not influence them at all (Fig. 3); there was no 
significant difference between the activities of 10 and $100 \mu \mathrm{g}$. PAS $/ \mathrm{ml}$. On the other hand, streptomycin alone, isoniazid alone and the combinations of streptomycin + isoniazid were all actively bactericidal, the activity of the higher concentrations being greater in each case.

It can be seen that NaPAS at $10 \mu \mathrm{g} . / \mathrm{ml}$. had no effect on the bactericidal activity of either streptomycin 2 units $/ \mathrm{ml}$., isoniazid $0.2 \mu \mathrm{g} . / \mathrm{ml}$. or the combination of these concentrations of streptomycin and isoniazid. However, the addition of NaPAS $100 \mu \mathrm{g} . / \mathrm{ml}$. slightly increased the activity of the higher concentrations of streptomycin, isoniazid and streptomycin + isoniazid. Thus, as is shown in Fig. 1, growth was obtained for the last time from the culture containing streptomycin 20 units $/ \mathrm{ml}$. on the 2 nd day of incubation, whereas the culture containing streptomycin $20 \mathrm{units} / \mathrm{ml}$. and PAS $100 \mu \mathrm{g} . / \mathrm{ml}$. yielded

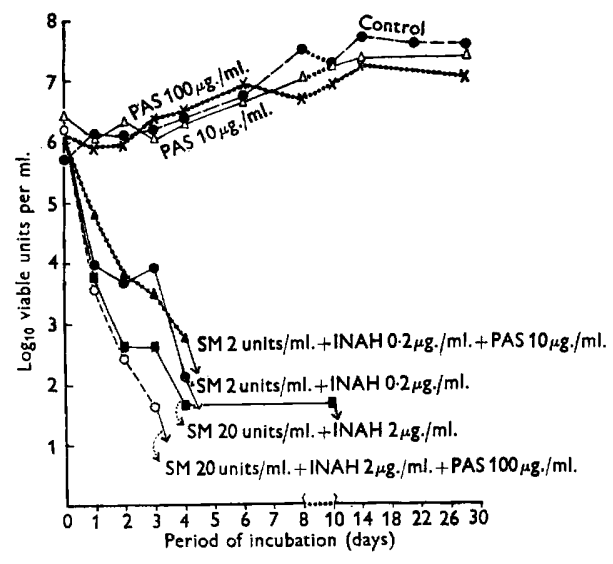

Fig. 3. Bactericidal action of combination of streptomycin, isoniazid and PAS.

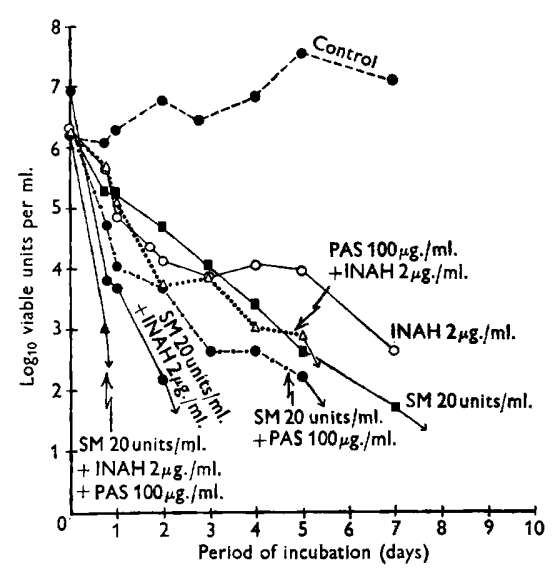

Fig. 4. Bactericidal action of streptomycin and isoniazid in combination with PAS.

no growth when sampled at 1 day. The bactericidal activity of isoniazid at $2 \mu \mathrm{g} . / \mathrm{ml}$. was less than that of isoniazid $2 \mu \mathrm{g} . / \mathrm{ml}$. +NaPAS $100 \mu \mathrm{g} . / \mathrm{ml}$. (Fig. 2) during the first 3 days of incubation, after which no comparison was possible because resistant bacilli grew in the culture containing isoniazid alone. Finally (Fig. 3) the last samples which yielded growth were obtained from the cultures containing streptomycin 20 units $/ \mathrm{ml}$. + isoniazid $2 \mu \mathrm{g} . / \mathrm{ml}$. on the 10th day, as compared with the 3rd day in the cultures containing these concentrations of streptomycin and isoniazid with the addition of NaPAS $100 \mu \mathrm{g} \cdot / \mathrm{ml}$.

This increase in the bactericidal activity of streptomycin 20 units $/ \mathrm{ml}$., isoniazid $2 \mu \mathrm{g} . / \mathrm{ml}$, and their admixture when combined with NaPAS $100 \mu \mathrm{g} . / \mathrm{ml}$. was confirmed in a fourth experiment (Fig. 4). Here it was noted that, although cultures were killed more rapidly by streptomycin +PAS than by streptomycin alone, the activity of streptomycin + isoniazid was greater. Thus the apparent synergistic activity of streptomycin and PAS was less than the synergistic activity of streptomycin and isoniazid. 
After 28 days of incubation about $2 \mathrm{ml}$. of each culture from Expt. 4 were injected into guinea-pigs. These animals were sacrificed 10 weeks later and the results of the post-mortem examinations are shown in Table 1 , together with the macroscopic appearances of the remainder of the cultures after 3 months of incubation. The culture containing streptomycin produced no lesions in the guinea-pig. However, the animal infected with the culture containing streptomycin + PAS developed tuberculous lesions from which were recovered tubercle bacilli resistant to streptomycin (resistance ratio of 128) but not to

\begin{tabular}{|c|c|c|}
\hline Drugs added to culture & $\begin{array}{l}\text { Tuberculous lesions } \\
\text { in guinea-pigs }\end{array}$ & $\begin{array}{l}\text { Macroscopic growth } \\
\text { after } 3 \text { months } \\
\text { incubation in culture }\end{array}$ \\
\hline \multirow{5}{*}{$\left.\begin{array}{l}\text { Nil } \\
\text { Streptomycin } 20 \mu \mathrm{g} \cdot / \mathrm{ml} \text {. } \\
\text { Streptomycin } 20 \mu \mathrm{g} . / \mathrm{ml} . \\
\text { + NaPAS } 100 \mu \mathrm{g} / \mathrm{ml} . \\
\text { Isoniazid } 2 \mu \mathrm{g} . / \mathrm{ml} . \\
\text { Isoniazid } 2 \mu \mathrm{g} . / \mathrm{ml} . \\
\text { + NaPAS } 100 \mu \mathrm{g} . / \mathrm{ml} .\end{array}\right\}$} & Extensive & + \\
\hline & None & - \\
\hline & Scanty & - \\
\hline & Local lesion & + \\
\hline & None & - \\
\hline
\end{tabular}

PAS. The remainder of this culture failed to show growth after 3 months of incubation. It is probable that very few resistant bacilli capable of growth in 20 units streptomycin $/ \mathrm{ml}$. were present in the cultures initially so that sampling variations might account for the failure of the culture containing streptomycin alone to produce lesions in the guinea-pig. The culture containing isoniazid alone eventually showed macroscopic growth of resistant bacilli and it produced local lesions only in the guinea-pig, as might be expected from the low pathogenicity of isoniazid-resistant strains to these animals (Barnett, Bushby \& Mitchison, 1953; Middlebrook \& Cohn, 1953; Mitchison 1954a). A resistant strain did not grow in the culture containing isoniazid + PAS. However, the lack of lesions in the animal infected with this culture should not be interpreted as necessarily meaning that no viable organisms were present, since a small number of isoniazid-resistant bacilli might fail to produce macroscopic disease. From this experiment one can conclude that although PAS may slightly increase the bactericidal activity of streptomycin or isoniazid during the early period when sensitive organisms are being killed, it may be unable to do more than prevent the growth of the resistant bacilli which survive this first phase.

The synergistic action of NaPAS $100 \mu \mathrm{g} . / \mathrm{ml}$. with streptomycin or isoniazid was found in a further two experiments, making 6 in all. However, it was not invariably reproducible, since it did not occur in part of a seventh experiment.

In sensitivity tests in Tween albumin medium the minimal inhibitory concentration of NaPAS became much lower as the size of the inoculum decreased (Mitchison \& Monk, to be published). Where the inoculum of bacilli in these tests resulted in a final concentration of about $10^{6}$ viable units $/ \mathrm{ml}$. (the same bacillary concentration as in our bactericidal experiments) the minimal inhibitory 
concentration was over $100 \mu \mathrm{g}$. NaPAS $/ \mathrm{ml}$. On the other hand, where the inoculum was about $10^{4}$ viable units $/ \mathrm{ml}$. growth was inhibited by less than $2 \mu \mathrm{g}$. NaPAS $/ \mathrm{ml}$. It therefore seemed possible that greater synergistic bactericidal activity might be shown if the initial inoculum acted on by the drugs were smaller. No such effect was found. The addition of NaPAS $10 \mu \mathrm{g} . / \mathrm{ml}$. did not increase the activity of either isoniazid $0.2 \mu \mathrm{g} . / \mathrm{ml}$. or of streptomycin 2 units $/ \mathrm{ml}$, when the initial concentrations of bacilli were between $10^{3}$ and $10^{4}$ viable units $/ \mathrm{ml}$.

\section{Drug resistance}

In two experiments the viable counts from cultures containing 2 units of streptomycin $/ \mathrm{ml}$. alone began to rise after the 1st week and eventually bacilli resistant to streptomycin were obtained. The admixture of NaPAS $10 \mu \mathrm{g} . / \mathrm{ml}$. with the streptomycin prevented the development of resistant strains in one of these experiments (Fig. 1) since the culture yielded no growth when sampled between the 5 th and 40 th days of incubation. However, in the other experiment this combination only slowed the growth of streptomycin-resistant bacilli which increased in numbers approximately 100-fold between the 6th and the 44th days. Isoniazid-resistant bacilli also grew rapidly in the culture containing isoniazid $\mathbf{0 \cdot 2} \mu \mathrm{g} . / \mathrm{ml}$. alone (Fig. 2). The combination of NaPAS $10 \mu \mathrm{g} . / \mathrm{ml}$. + isoniazid $0 \cdot 2 \mu \mathrm{g} . / \mathrm{ml}$. again only delayed the growth of bacilli resistant to isoniazid and PAS for about a month. Thus one can conclude that NaPAS in the low therapeutic concentration of $10 \mu \mathrm{g} . / \mathrm{ml}$. may only delay the emergence of resistance.

Resistant strains only appeared in one out of three cultures containing streptomycin 20 units $/ \mathrm{ml}$. presumably because of the small number of mutant bacilli in the initial bacterial population which were capable of growth in this drug concentration. However, resistant strains developed in none of the corresponding cultures containing NaPAS $100 \mu \mathrm{g} . / \mathrm{ml}$. + streptomycin 20 units/ ml., neither did one occur in the culture containing NaPAS $100 \mu \mathrm{g} . / \mathrm{ml} .+$ streptomycin 2 units $/ \mathrm{ml}$. Furthermore, the addition of NaPAS $100 \mu \mathrm{g} . / \mathrm{ml}$. to isoniazid $2 \mu \mathrm{g} . / \mathrm{ml}$. prevented the appearance of isoniazid-resistant bacilli in the experiments shown in Figs. 2 and 4. There is therefore some evidence that resistance is less likely to emerge in cultures containing mixtures of the higher concentrations of PAS and streptomycin than in those with the lower concentrations.

\section{DISCUSSION}

The method of measuring the bactericidal activity of the drugs that we have used may be criticized on two grounds. In the first place the addition of PAS might have caused clumping of the bacilli. This seems improbable since, in the cultures containing PAS alone, the viable counts were the same as in the control drug-free cultures after the initial phase of slight inhibition was over. Secondly, carry-over of the drugs from the cultures might have inhibited the growth of surviving bacilli. This possibility was minimized by the small sample ( 1 loopful) removed from the cultures and by the large area on the plate over 
which each sample was spread. Nevertheless, a concentration of NaPAS $100 \mu \mathrm{g} . / \mathrm{ml}$. is about 100 times that necessary to inhibit growth of sensitive bacilli on solid media, so that some of the counts of $<10^{3}$ viable units/ml. taken from cultures containing $100 \mu \mathrm{g}$. NaPAS $/ \mathrm{ml}$. may have been diminished by carry-over of this compound.

Bearing in mind these criticisms of the method it remains probable that there was some synergistic bactericidal activity between PAS and isoniazid, PAS and streptomycin and between PAS and streptomycin + isoniazid, when these drugs were present in high concentrations. This synergism was weak and not always reproducible, but it stands in contrast to the antagonistic activity of terramycin (oxytetracycline), which was shown by Mackaness \& Smith (1953) to prevent the bactericidal action of isoniazid on tubercle bacilli. Thus although both PAS and terramycin, when acting alone, appear primarily bacteriostatic, their modifications of the actions of such bactericidal drugs as streptomycin and isoniazid are different.

From the clinical point of view any synergistic bactericidal activity of PAS would seem to be too small to influence the response of patients to treatment with streptomycin or isoniazid. Groups of patients treated with either streptomycin + isoniazid, isoniazid + PAS or with streptomycin + isoniazid + PAS, showed the same radiological and bacteriological improvement in a United States Public Health Service Investigation (Ferebee \& Mount, 1954). In treatment, the superiority of streptomycin + PAS over streptomycin alone (Medical Research Council, 1950) and the probable superiority of isoniazid + PAS over isoniazid alone (Medical Research Council, 1953c) is therefore likely to be due largely to the suppression of drug resistance.

Our finding that combinations of low concentrations of PAS and isoniazid or streptomycin only delayed the emergence of drug-resistant bacilli, whereas combinations of high concentrations suppressed their growth, is consistent with results of the Medical Research Council (1952) trial in which streptomycinresistant strains were obtained more frequently from patients treated with streptomycin and a low dosage of PAS (5 or $10 \mathrm{~g}$. NaPAS/day), than in those treated with streptomycin and a high dosage of PAS (20 g. NaPAS/day). In contrast the number of isoniazid-resistant strains isolated did not differ significantly when isoniazid was given with $10 \mathrm{~g}$. NaPAS/day or when it was given with 20 g. NaPAS/day (Medical Research Council, 1953c.). However, the manner in which the doses of PAS were administered differed in these two trials. When given with streptomycin the number of doses during the day was constant, so that the peak serum concentrations following the smaller doses would have been lower. On the other hand, when given with isoniazid the total amount of PAS given in each dose was the same, but the frequency of administration was halved, so the peak serum concentrations during high or low total daily dosage would have been similar. We have no information on the relation between fluctuations in the concentrations of PAS in serum and in the tissues, but it remains possible that the height of peak serum concentrations may be a more important determining factor in preventing drug resistance during combined therapy than the maintenance of a high average concentration. 


\section{REFERENCES}

AItoFr, R. J. W. (1952). Action in vitro de l'hydrazide de l'acide isonicotinique seul et combiné avec d'autres produits. Ann. Inst. Pasteur, 83, 130.

Barnett, M., Bushby, S. R. M. \& Mrtchison, D. A. (1953). Tubercle bacilli resistant to isoniazid; virulence and response to treatment with isoniazid in mice and guinea pigs. Brit. J. exp. Path. 34, 568.

Ferebee, S. H. \& Mount, F. W. (1954). Progress report on therapeutic and toxic effects of combinations of isoniazid, streptomycin and para-aminosalicylic acid. Amer. Rev. Tuberc. 69, 1.

Graessle, O. E. \& Pietrowski, J. J. (1949). The in vitro effect of para-aminosalicylic acid (PAS) in preventing acquired resistance to streptomycin by Mycobacterium tuberculosis. J. Bact. 57, 459.

Knox, R., KING, M. B. \& Woodroffe, R. C. (1952). In vitro action of isoniazid on Mycobacterium tuberculosis. Lancet, ii, 854.

LehmanN, J. (1946). Para-aminosalicylic acid in the treatment of tuberculosis. Lancet, $\mathrm{i}, 15$.

McClosky, W. T., Smrth, M. I. \& Frias, J. E. G. (1948). The action of $p$-aminosalicylic acid (PAS) in experimental tuberculosis. J. Pharmacol. 92, 447.

Mackaness, G. B. \& Smith, N. (1953). The bactericidal action of isoniazid, streptomycin, and terramycin on extracellular and intracellular tubercle bacilli. Amer. Rev. Tuberc. 67, 322.

Medical Research Council (1948). Streptomycin treatment of pulmonary tuberculosis. Brit. med. J. ii, 769 .

Medical Research Council (1950). Treatment of pulmonary tuberculosis with streptomycin and para-aminosalicylic acid. Brit. med. J. ii, 1073.

Medical Research Council (1952). The prevention of streptomycin resistance by combined therapy. Brit. med. J. i, 1157.

Medical Research Council (1953a). Laboratory techniques for the determination of sensitivity of tubercle bacilli to isoniazid, streptomycin and PAS. Lancet, ii, 213.

Medical Research Council (1953b). Emergence of bacterial resistance in pulmonary tuberculosis under treatment with isoniazid, streptomycin plus PAS, and streptomycin plus isoniazid. Lancet, ii, 217.

Medical Research Council (1953c). Isoniazid in combination with streptomycin or with PAS in the treatment of pulmonary tuberculosis. Brit. med. J. ii, 1005.

Middlebrook, G. \& Cohn, M. L. (1953). Some observations on the pathogenicity of isoniazid-resistant variants of tubercle bacilli. Science, 118, 297.

MItchison, D. A. (1952). Titration of strains of tubercle bacilli against isoniazid. Lancet, ii, 858.

Mrrchison, D. A. (1953). The occurrence of independent mutations to different types of streptomycin resistance in Bacterium coli. J. gen. Microbiol. 8, 168.

Mitchison, D. A. (1954a). Tubercle bacilli resistant to isoniazid; virulence and response to treatment with isoniazid in guinea pigs. Brit. med. J. i, 128.

Mrtchison, D. A. (1954b). Problems of drug resistance. Brit. med. Bull. 10, 115.

Newhouse, J. P. \& Klyne, W. (1949). Determination of $p$-aminosalicylic acid in body fluids. Biochem. $J .44$, vii.

Nilsson, H. (1953). The concentration of PAS in the blood during medication with PAS or PAS salts. Tubercle, Lond. 34, 100.

Singh, B. \& Mitchison, D. A. (1954). Bactericidal activity of streptomycin and isoniazid against tubercle bacilli. Brit. med. J. i, 130.

SteEnken, W. \& Wolinsky, E. (1950). Effects of antimicrobial agents on the tubercle bacillus and on experimental tuberculosis. Amer. J. Med. 9, 633. 
Swedrung, B. (1949). Further experiences in the treatment of experimental tuberculous infection in white mice by para-aminosalicylic acid (PAS) employing chemosensitive and chemo-resistant strains of tubercle bacillus. Acta med. scand. 135, 289.

Swedrurg, B. \& Widstrom, G. (1948). Treatment of experimental tuberculosis in mice and guinea pigs with para-aminosalicylic acid (PAS) and streptomycin. Acta med. scand. $131,116$.

Vennesland, K., Ebert, R. H. \& Bloch, R. G. (1948). In vitro effect of streptomycin and para-aminosalicylic acid (PAS) on the growth of tubercle bacilli. Proc. Soc. exp. Biol., N.Y. 68, 250.

(Received 5 August 1954) 